\title{
Valoración de aspectos éticos y metodológicos en un estudio cualitativo con personas usuarias de Oncología Pediátrica
}

Assessment of ethical and methodological aspects in a qualitative study with health care users in Paediatric Oncology

\author{
María J. Escudero Carretero ${ }^{\mathrm{I}, 2}$ \\ Noelia García Toyos ${ }^{I}$ \\ Amelia I. Martín Barato ${ }^{I}$ \\ Ainhoa Ruiz Azarola ${ }^{\mathrm{I}}$ \\ Olivia Pérez Corral ${ }^{\mathrm{I}}$ \\ Ma Ángeles Prieto Rodríguez ${ }^{\mathrm{I}, 2}$ \\ Amets Suess Schwend ${ }^{1,2}$ \\ ${ }^{\mathrm{I}}$ Escuela Andaluza de Salud Pública, Granada \\ ${ }^{2}$ CIBER de Epidemiología y Salud Pública (CIBERESP), Espańa \\ amets.suess.easp@juntadeandalucia.es (ESPAÑA)
}

Recibido: 26.04.2016

Aceptado: 28.11.2016

\section{RESUMEN}

Fundamentos: En el marco de una investigación cualitativa con personas usuarias de Oncología Pediátrica y sus acompañantes, se diseñó y aplicó un instrumento de autoevaluación sobre aspectos éticos y metodológicos del estudio.

Métodos: Investigación cualitativa con personas usuarias de Oncología Pediátrica y sus acompañantes, en cuatro hospitales del Sistema Sanitario Público de Andalucía. Elaboración y aplicación de un instrumento de autoevaluación. Análisis descriptivo, semántico y pragmático de contenido y triangulación por el equipo investigador.

Resultados: Las personas integrantes del equipo de investigación señalan 1. La utilidad del formulario de Consentimiento Informado en formato de cómic en una investigación con niños/as, dentro de un enfoque más amplio de ética de la investigación, 2. La valoración positiva de las técnicas creativas, destacando 
la necesidad de una aplicación diferenciada, 3. La importancia de una reflexión sobre la vivencia del proceso de investigación.

Conclusiones: La aplicación de un instrumento de autoevaluación se identifica como una herramienta útil para valorar aspectos éticos, metodológicos y autorreflexivos en un estudio cualitativo con menores de edad.

\title{
PALABRAS CLAVE
}

Oncología Pediátrica, investigación cualitativa, ética de la investigación, menores, investigación basada en las artes.

\begin{abstract}
Background: In the context of a qualitative research with health care users in Paediatric Oncology and their family members, a self-assessment tool regarding ethical and methodological aspects of the study has been designed and implemented.

Methods: Qualitative research with health care users in Paediatric Oncology and companions, in four hospitals from the Andalusian Public Healthcare System. Development and implementation of a self-assessment tool. Descriptive, semantic and pragmatic content analysis and triangulation conducted by the research team.

Outcomes: The members of the research team highlight: 1 . The usefulness of a cartoon-style Informed Consent form in a qualitative study with children, within a broader approach to research ethics, 2 . The favourable assessment of the creative techniques, stressing the need for a differentiated application, and 3 . The importance of reflecting on the experience of the research process.

Conclusions: The application of a self-assessment tool is identified as a useful tool for evaluating ethical, methodological and self-reflective aspects in a qualitative study conducted with minors.
\end{abstract}

\section{KEY WORDS}

Paediatric Oncology, Qualitative Research, Research Ethics, Minors, Arts-Based Research.

\section{INTRODUCCIÓN}

A lo largo de los últimos años, la inclusión de la perspectiva de las personas usuarias en los procesos de mejora de la calidad asistencial ha adquirido una creciente importancia (Teunissen et al. 2011), contribuyendo al desarrollo de metodologías específicas dentro de un amplio campo de investigación cualitativa 
aplicada al ámbito de la salud (Amezcua y Gálvez Toro 2002; Conde y Andrés 1995; Ulin, Robinson y Tolley eds. 2005). Dentro de un análisis de la calidad asistencial percibida, el conocimiento de la experiencia de menores de edad se puede identificar como un área de estudio emergente que plantea cuestiones éticas y metodológicas específicas (Ångström-Brännström, Norberg y Jansson 2008; Curtis et al. 2004; Duncan et al. 2009; Gibson et al. 2010; González-Gil 2005; Mah et al. 2006; March et al. 2003; Ullán et al. 2012; Woodgate y Degner 2003).

Desde el descubrimiento de casos históricos de abusos en la realización de estudios científicos con grupos vulnerables (Beecher 1996), entre ellos con personas menores de edad (Goldby 1971), se desarrollaron principios éticos específicos para la investigación con este grupo de población que parten, entre otros, de la consideración de una especial vulnerabilidad de personas menores, el derecho a la protección de daños físicos y psíquicos, la necesidad de una ponderación exhaustiva de riesgos y beneficios, así como el derecho a la información y participación, en coherencia con el principio de desarrollo progresivo de sus capacidades (Corporació Parc Taulí 2003; De Abajo 1997; Galende 2012; Mack, Giarelli y Bernhardt 2009; Mason y Hood 2011; Pickler 2010; Sammons y Starkey 2011; Shaw, Brady y Davey 2011; Wellesley y Jenkins 2012; Wilkinson 2000; Ybarra et al. 2009).

Respecto a los procesos de Consentimiento Informado en la investigación con menores de edad (Duncan et al. 2009; Shaw, Bray y Davey 2011; Wellesley y Jenkins 2012), se señala el requisito de un Consentimiento Informado por parte de los padres/madres o tutores legales, paralelamente al derecho de la persona menor a consentir o rechazar la participación, limitado solo en caso de una investigación terapéutica en la que la no participación pondría en riesgo la vida de la persona menor. Además, se aportan reflexiones críticas respecto a un potencial conflicto entre la necesidad de protección específica relacionada con el estatus como grupo vulnerable y el derecho a la participación (Carter 2009; Part y Grayson 2008; Chen y Sheperd 2009), así como con relación a los riesgos inherentes a un menor desarrollo de una investigación con menores de edad en consecuencia de las dudas éticas planteadas (Sammons y Starkey 2011; Carter 2009; Part y Greyson 2008). Asimismo, se revisa críticamente el requisito de un consentimiento parental, especialmente en caso de participantes adolescentes (Chen y Sheperd 2009). Desde una perspectiva de Derechos Humanos, se reafirma el derecho a la información y la participación en procesos de decisión en el ámbito sanitario en documentos internacionales, entre ellos la Convención sobre los Derechos del Niño (ONU 1989 [1990]) y los Comentarios Generales $\mathrm{N}^{\mathrm{o}}$ 7, 12 y 15 del Comité de los Derechos del Niño (ONU 2005, 2009, 2013).

La preocupación sobre el cuidado de los aspectos éticos en la investigación con menores de edad no se limita al ámbito de los ensayos clínicos. Dentro de reflexiones sobre aspectos éticos en la investigación cualitativa en salud en general (Barrio-Cantalejo y Simón-Lorda 2006), se identifican riesgos específicos en su aplicación a menores de edad, entre ellos un mayor desequilibrio de poder, debido a la mayor diferencia de edad entre la persona 
que entrevista y la persona entrevistada (Duncan et al. 2009; Wilkinson 2000), el especial impacto emocional de preguntas sobre aspectos sensibles en caso de personas menores de edad (Wilkinson 2000; Ybarra et al. 2009), así como una mayor vulnerabilidad relacionada con una frecuente falta de reconocimiento de las personas menores de edad como sujetos de derechos (Ybarra et al. 2009). Como potenciales beneficios de una investigación cualitativa con personas usuarias menores de edad se resalta el reconocimiento de su derecho a la participación (Gibson et al. 2010; Wilkinson 2000), la valoración de su rol como agentes activos (Mason y Hood 2011), el efecto de empoderamiento (Wilkinson 2000) y la oportunidad de mejora de los servicios desde el conocimiento de sus opiniones (Wilkinson 2000).

Aparte de la consideración de los aspectos éticos, la investigación con menores de edad plantea cuestiones metodológicas específicas. Dentro de un campo emergente de investigación basada en las artes (Finley 2005; Knowles y Cole 2008; McNiff 1998), se proponen diferentes metodologías creativas aplicadas a una investigación con niños y niñas, incluyendo el uso de técnicas como el dibujo, el role playing, las marionetas o la fotografía (Carter y Ford 2013; Coad, Plumridge y Metcalfe 2009; Einarsdottir 2005; González-Gil 2007; Kondo y Sjöberg 2012; Mand 2012; March et al. 2003; Trell y Van Hoven 2010; Wilkinson 2000).

Como beneficios del uso de métodos creativos en la investigación cualitativa con personas menores de edad, se señala la especial adecuación del lenguaje creativo a las capacidades expresivas de los/as niños/as (Carter y Ford 2013; González-Gil 2007), el fomento de su participación (Mand 2012; Trell y Van Hoven 2010) y la facilitación de la expresión de sus opiniones (Carter y Ford 2013; Wilkinson 2000). Además, se enfatiza la oportunidad de una disminución del desequilibrio de poder mediante la actividad creativa (Kondo y Sjörberg 2012; Mand 2012; Wilkinson 2000), así como de una expresión de temáticas de carácter personal o emocional a través del lenguaje creativo (Coad, Plumridge y Metcalfe 2009; Trell y Van Hoven 2010; Wilkinson 2000). En el ámbito de la evaluación de la calidad asistencial percibida con personas menores de edad, estas técnicas han encontrado un campo amplio de aplicación (Carter y Ford 2013; González-Gil 2007; March et al. 2003).

Desde el interés de incluir la perspectiva de personas usuarias menores de edad en los procesos de mejora en el ámbito clínico, en 2010 y 2011 se realizó un análisis de la calidad asistencial percibida con personas usuarias de servicios de Oncología Pediátrica y sus acompañantes en cuatro hospitales del Servicio Sanitario Público de Andalucía (SSPA), mediante una investigación cualitativa que incluyó el uso de técnicas creativas. Después de la realización del trabajo de campo, se llevó a cabo un proceso de evaluación de aspectos éticos y metodológicos por parte de integrantes del equipo de investigación. En el presente artículo, se retrata 1. La consideración de aspectos éticos en el proceso de investigación, 2. La evaluación del uso de metodologías creativas en el proceso de entrevista con personas usuarias menores de edad y 3. Las reflexiones de las personas integrantes del equipo de investigación sobre su vivencia 
en el proceso de investigación. En este artículo, se resumen las reflexiones sobre aspectos metodológicos y éticos, así como la vivencia del proceso de investigación, sin profundizar en la valoración de la calidad asistencial percibida y propuestas de mejora aportadas por las personas entrevistadas que será objeto de futuras publicaciones.

El análisis se inserta en una perspectiva de ética reflexiva y dialógica (Cannella y Lincoln 2007), el marco de Derechos Humanos relacionado con la infancia (ONU 2005, 2009, 2013) y enfoques participativos en la investigación con menores de edad (Wilkinson 2000).

\section{SUJETOS Y MÉTODOS}

En 2010 y 2011, se realizó una investigación cualitativa con personas usuarias de Oncología Pediátrica, en distintas fases de enfermedad, de edades entre los 5 y 16 años, así como sus acompañantes, en cuatro hospitales del Servicio Sanitario Público de Andalucía, con el objetivo de conocer la calidad asistencial percibida durante la hospitalización. En total, se entrevistó a 33 personas usuarias y 47 acompañantes (Tabla I).

Tabla I: Metodología del estudio Análisis de calidad percibida y expectativas de personas usuarias de Oncología Pediátrica y sus acompañantes

\begin{tabular}{|l|l|}
\hline Diseño: & $\begin{array}{l}\text { Diseño cualitativo a partir de diferentes técnicas grupales e } \\
\text { individuales. }\end{array}$ \\
\hline Sujetos de estudio: & $\begin{array}{l}\text { Niños y niñas con diagnóstico de cáncer (enfermedades } \\
\text { hematológicas y tumores sólidos), así como sus acompañantes. }\end{array}$ \\
\hline Ámbito de & $\begin{array}{l}\text { Andalucía, en los siguientes 4 hospitales de referencia: Hospital } \\
\text { Universitario Virgen de las Nieves (Granada), Hospital General } \\
\text { estudio: }\end{array}$ \\
$\begin{array}{l}\text { Universitario Reina Sofía (Córdoba), Hospital Universitario } \\
\text { Virgen del Rocío (Sevilla), Hospital Regional Universitario } \\
\text { Carlos Haya (Málaga). }\end{array}$ \\
\hline
\end{tabular}




\begin{tabular}{|c|c|}
\hline $\begin{array}{l}\text { Muestreo y perfil } \\
\text { de participantes: }\end{array}$ & $\begin{array}{l}\text { Muestreo intencionado según perfiles basado en criterios de } \\
\text { inclusión y exclusión. Dos grupos de participantes: personas } \\
\text { usuarias y sus acompañantes. } \\
\text { Criterios de segmentación: según fase de enfermedad y edad de } \\
\text { la persona usuaria } \\
\text { o Fases de evolución de la enfermedad: 1) Tratamiento } \\
\text { convencional: una vez confirmado el diagnóstico } \\
\text { oncológico y recibiendo tratamiento con quimioterapia } \\
\text { y/o radioterapia. 2) Enfermedad avanzada: recibiendo } \\
\text { tratamiento paliativo. } \\
\text { o Edad: 1) de } 5 \text { a } 10 \text { años } 2 \text { ) de } 11 \text { a } 16 \text { años. } \\
\text { Criterios de inclusión para personas usuarias: } \\
\text { Niños y niñas con diagnóstico de cáncer } \\
\text { (hematológicos y tumores sólidos). } \\
\circ \quad \text { Hospitalizaciones de más de } 3 \text { días de duración. } \\
\circ \quad \text { Grupos de edad: } 5-10 \text { y } 11-16 \text { años. } \\
\text { Criterios de exclusión para personas usuarias: } \\
\circ \quad \text { Hospitalización por trasplante de médula ósea. } \\
\circ \quad \text { Tener alguna dificultad física o psíquica que le } \\
\text { imposibilite la participación en el estudio. } \\
\text { Estar en hospitalización en fase de diagnóstico. } \\
\text { Criterios de inclusión para acompañantes: } \\
\circ \quad \text { Ser acompañante de una niña o niño con diagnóstico } \\
\text { de cáncer, ingresado/a en el servicio de Oncología } \\
\text { Pediátrica durante más de tres días y que cumpliera el } \\
\text { resto de criterios de inclusión arriba especificados. } \\
\text { Criterios de exclusión para acompañantes: Ídem que personas } \\
\text { usuarias. }\end{array}$ \\
\hline $\begin{array}{l}\text { Composición de la } \\
\text { muestra: }\end{array}$ & $\begin{array}{l}\text { Participaron } 33 \text { niñas/os y } 47 \text { acompañantes. } \\
\text { Grupo de personas usuarias: 33; género: } 14 \text { niñas y } 19 \text { niños; } \\
\text { edades de } 5 \text { a } 16 \text { años, media de edad: } 9 \text { ' } 6 \text { años; tipo de } \\
\text { tumor: } 10 \text { leucemias y } 23 \text { tumores sólidos; fase: } 27 \text { tratamiento } \\
\text { convencional y } 6 \text { fase avanzada de la enfermedad. } \\
\text { Grupo de acompañantes: } 47 \text { personas; género: } 30 \text { mujeres y } \\
17 \text { varones; edad: entre } 25 \text { y } 57 \text { años, media de } 40 \text {; distintas } \\
\text { profesiones y niveles de estudios; fase: } 39 \text { tratamiento } \\
\text { convencional y } 9 \text { en fase avanzada de la enfermedad. }\end{array}$ \\
\hline
\end{tabular}


Métodos: En el marco de un diseño cualitativo, se utilizó la técnica de entrevista semiestructurada con todas las personas participantes, así como técnicas creativas con las personas usuarias menores de edad, tanto en sesiones individuales como grupales (Gráfico 1). La entrevista semiestructurada partió de un guion de preguntas que se adaptaron según la edad de la persona entrevistada y el desarrollo de su narrativa, con el objetivo de facilitar una libre expresión de su experiencia. Las técnicas creativas se llevaron a cabo dentro de un juego ('búsqueda del tesoro') e incluían dibujo, collage, role-playing, cine-foro, asociación de imágenes con conceptos, entrevistas con marionetas y redacción de cartas (Tabla II). En las sesiones grupales, se buscó una homogeneidad intragrupal respecto a edad y fase de enfermedad.

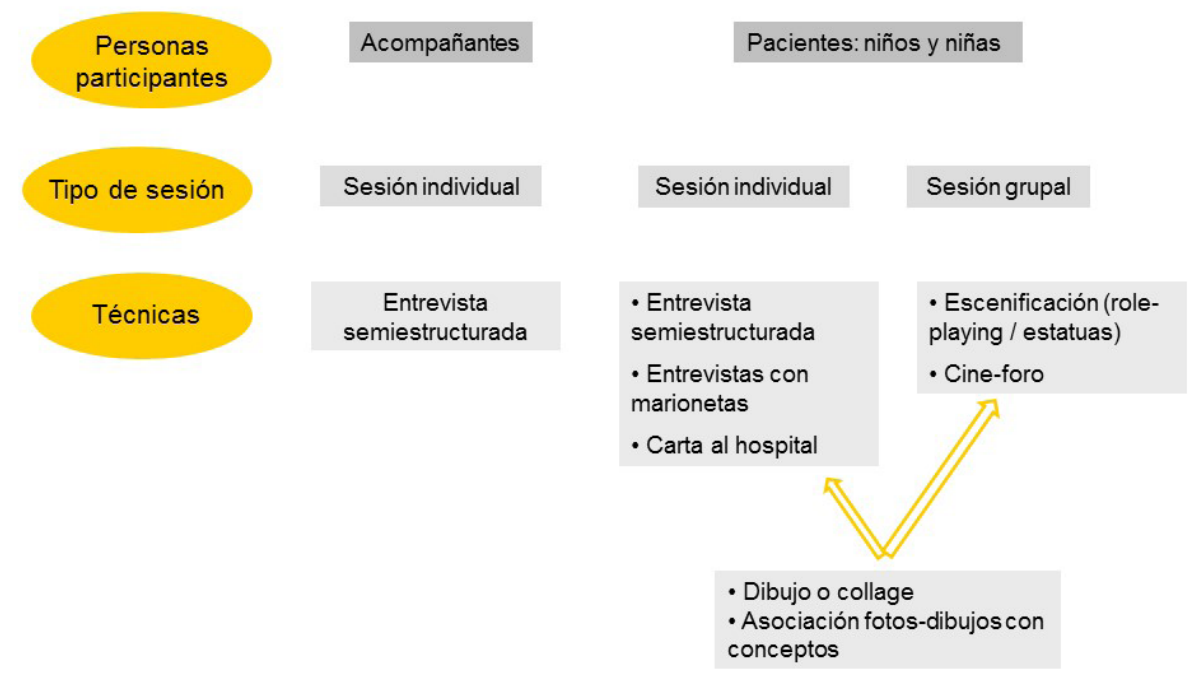

Gráfico 1: Metodología de la investigación 


\begin{tabular}{|c|c|c|c|c|c|c|c|c|}
\hline 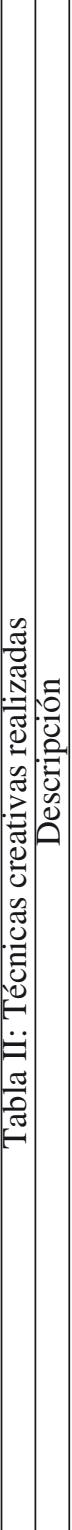 & 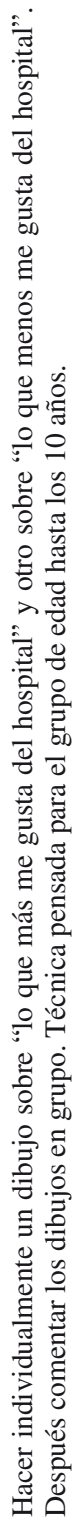 & 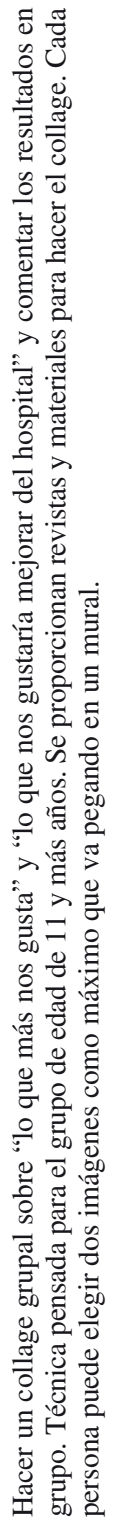 & 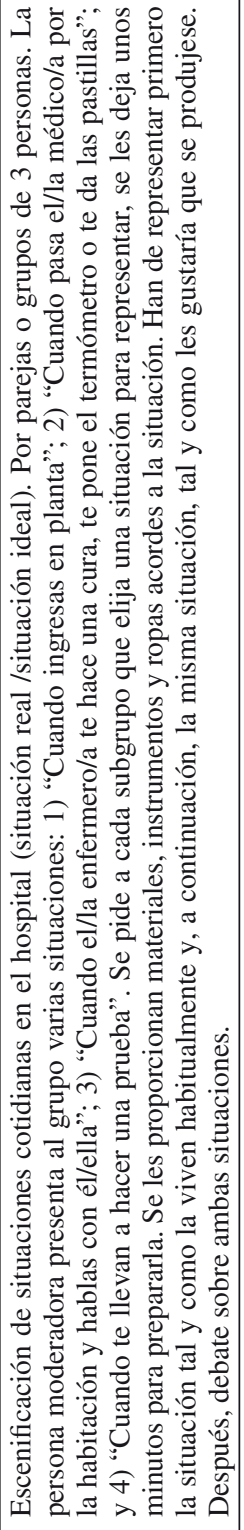 & 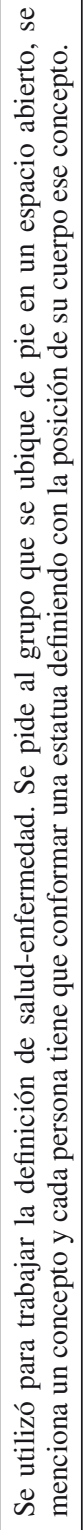 & 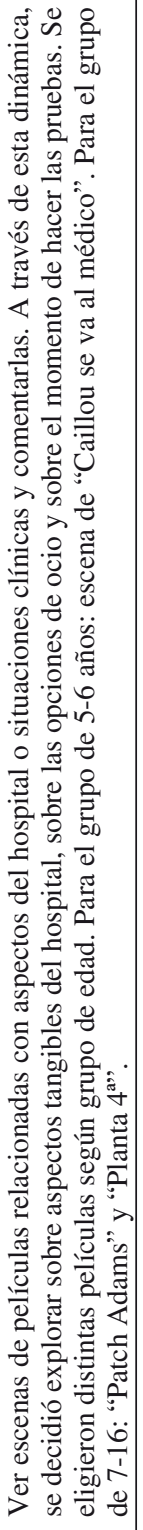 & 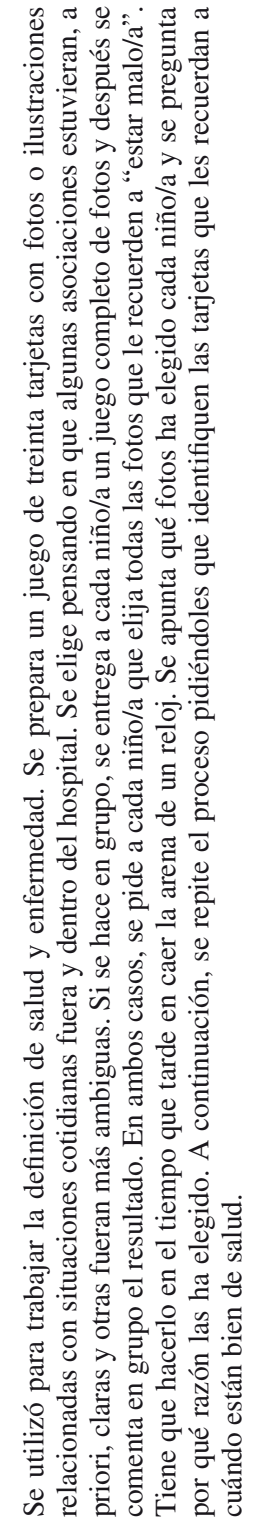 & 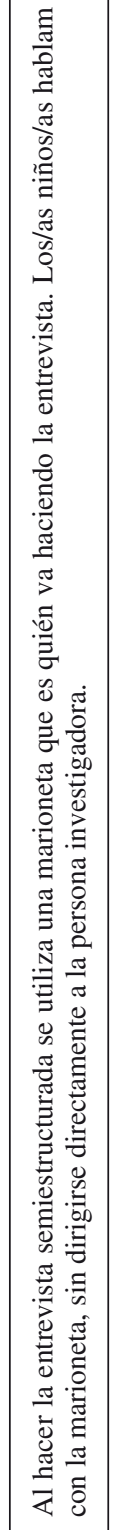 & 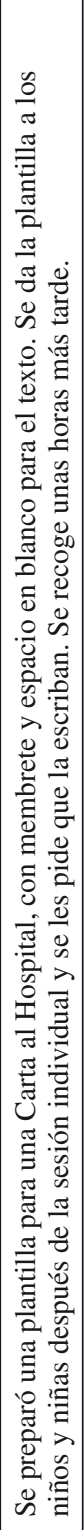 \\
\hline & $\begin{array}{l}\stackrel{0}{\vec{z}} \\
\stackrel{\overrightarrow{0}}{\circ}\end{array}$ & $\frac{\frac{\sigma}{\sigma}}{\overline{0}}$ & 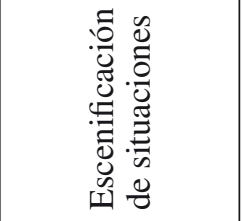 & 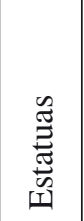 & $\Xi$ & 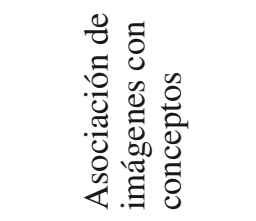 & 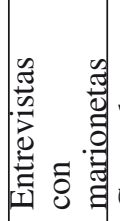 & \\
\hline
\end{tabular}


Análisis de datos: Las entrevistas individuales y sesiones en grupo se grabaron y se transcribieron. La información verbal obtenida en ambos formatos se sometió a un análisis descriptivo, semántico y pragmático de contenido, en el sentido de una identificación de temas compartidos y aspectos diferenciales en las narrativas de las personas participantes, teniendo en cuenta su contexto social y personal (Amezcua y Toro 2002). En el análisis del material visual y de las escenificaciones, se tomó como punto de partida las explicaciones que las personas participantes habían aportado sobre sus propias imágenes y representaciones teatrales, en coherencia con métodos de elicitación visual (Johnson y Well 2001). Para buscar la validez de los resultados se realizó un proceso de triangulación tanto de técnicas, de resultados y de interpretaciones por diferentes integrantes del equipo de coordinación.

Aspectos éticos: Los aspectos éticos se tuvieron en cuenta en diferentes momentos del estudio: 1. En la selección de los/as participantes, 2. En el abordaje de los aspectos emocionales en el proceso de entrevista, 3. Mediante el proceso de información y Consentimiento Informado, así como 4. En la protección de la confidencialidad de datos, en coherencia con la Ley Orgánica 15/1999, de 15 de diciembre y 5. En la devolución de resultados a las personas participantes.

Respecto al Consentimiento Informado (CI), en caso de las personas acompañantes, se les entregó una hoja informativa por escrito y el formulario de CI. En caso de las personas usuarias menores de edad, se elaboró un formulario de información y Consentimiento Informado en formato cómic, en dos versiones adaptadas a las franjas de edad establecidas (5-10 y 11-16 años) (Gráfico 2 y 3). Se solicitó a los y las acompañantes verbalmente y por escrito la autorización para la participación de las personas usuarias menores de edad. En todos los documentos se especificó el permiso para la grabación de audio y publicación o utilización posterior de la información obtenida, incluyendo dibujos, cartas u otros productos creativos. 

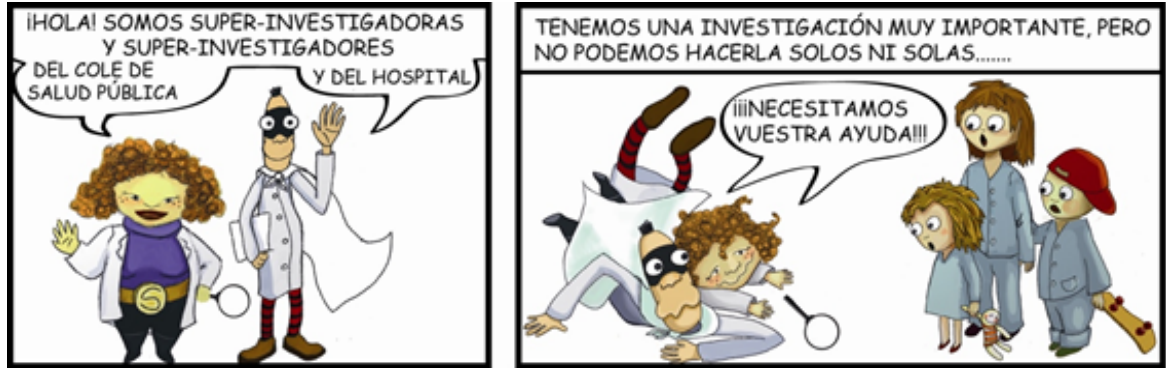

QUEREMOS INVESTIGAR Y BUSCAR CONTIGO, QUE NOS AYUDES CON TU SUPERPODER DE VER LAS COSAS BUENAS DEL HOSPITAL Y LAS QUE TE GUSTARÍA MEJORAR...

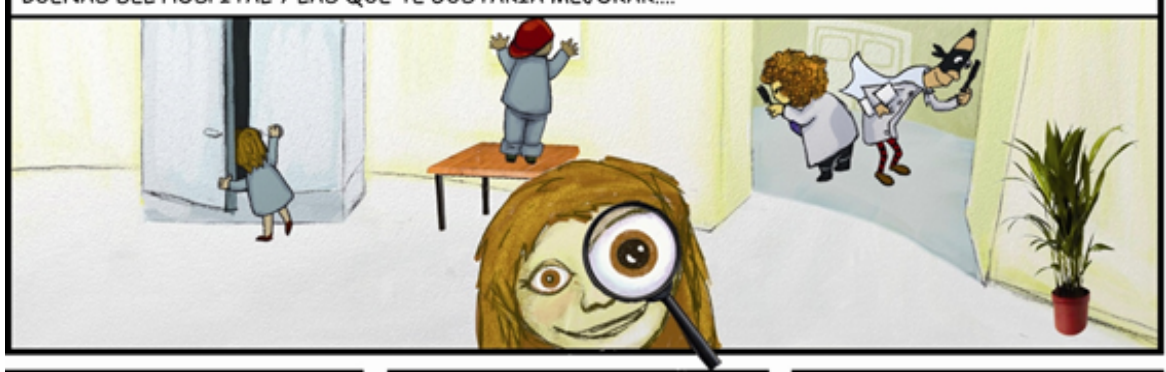

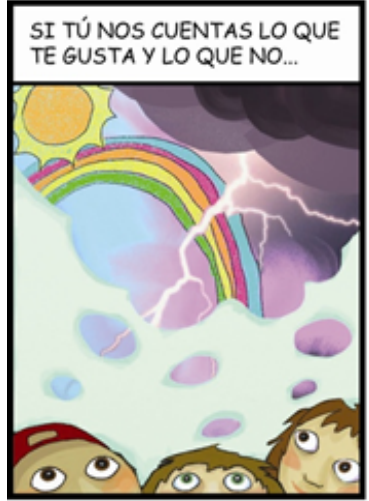

ESO SI, TU IDENTIDAD SERÁ SECRETA.
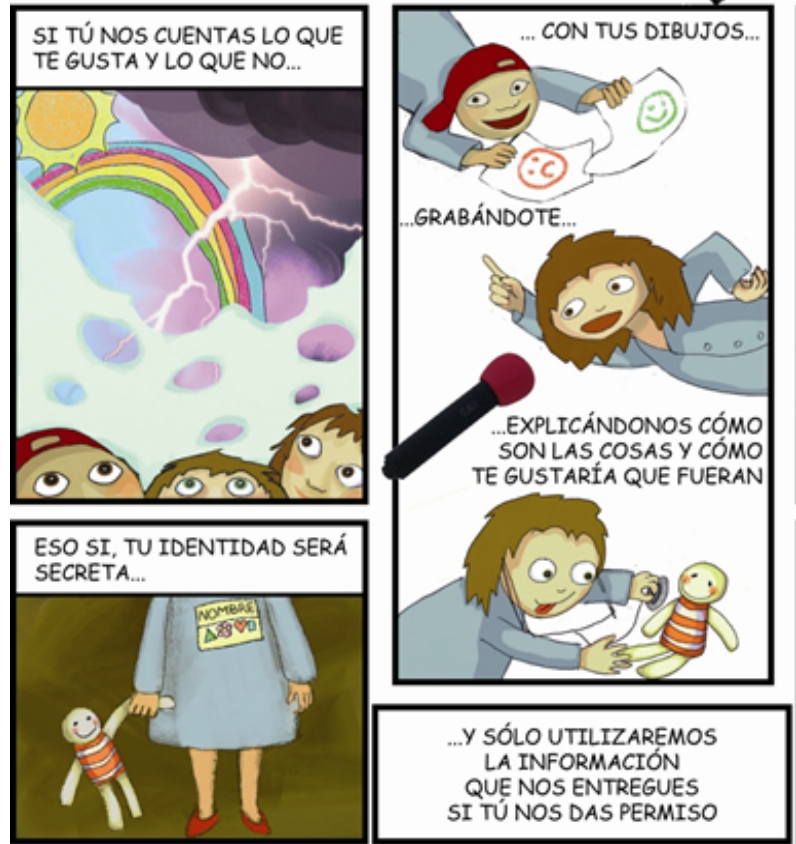

Gráfico 2: Consentimiento en formato cómic (5-10 años) 


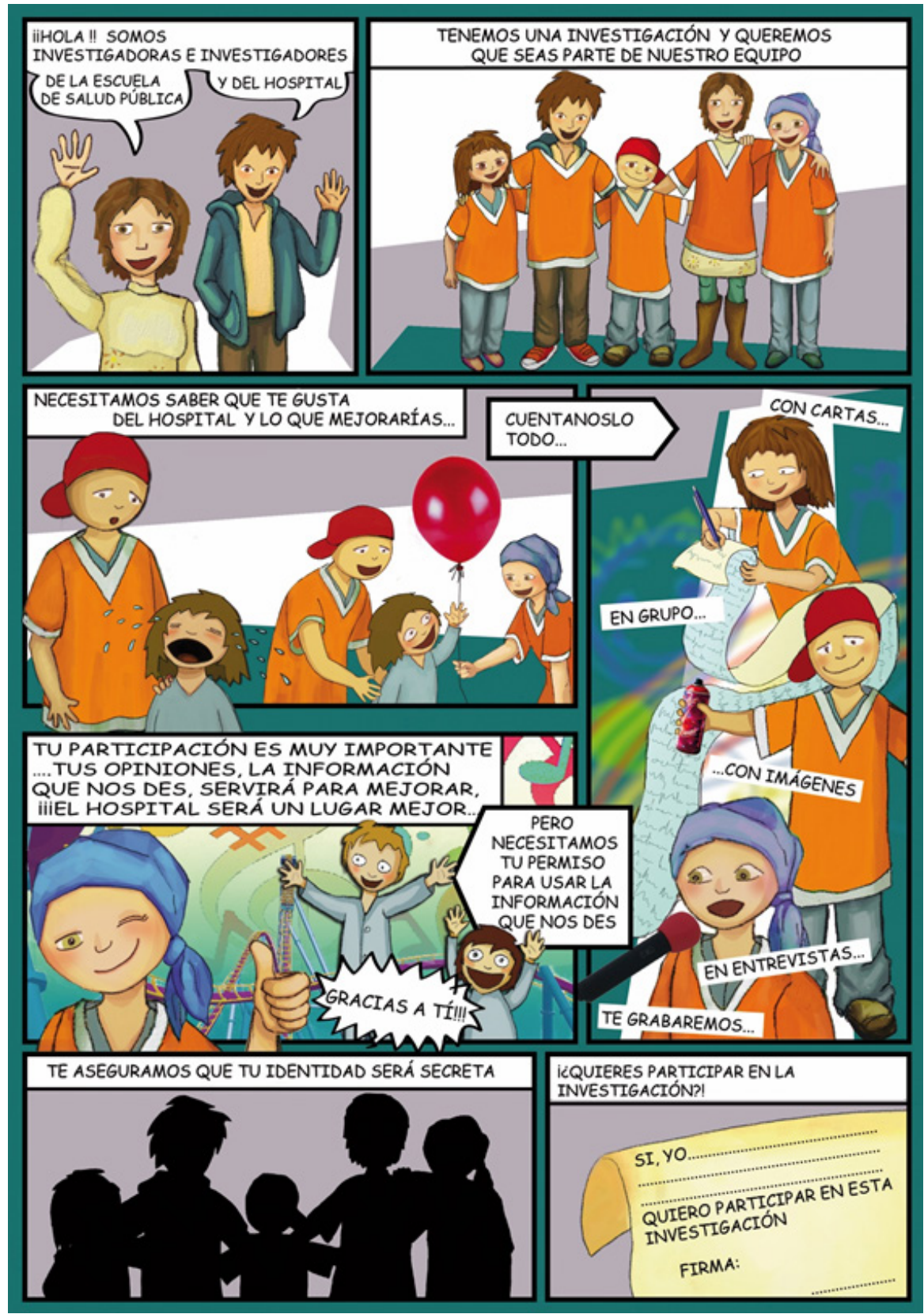

Gráfico 3: Consentimiento en formato cómic (11-16 años) 
Evaluación de los aspectos metodológicos y éticos: Posteriormente al proceso de trabajo de campo y análisis de resultados, se realizó una valoración de aspectos metodológicos y éticos del estudio, mediante un instrumento diseñado y aplicado por el equipo de investigación (Tabla III). El instrumento permitió al equipo calificar, valorar y analizar 1. Los aspectos éticos, 2. Los aspectos metodológicos y 3 . La vivencia personal del equipo investigador durante el proceso de trabajo de campo. Después de la cumplimentación del instrumento de evaluación, dos integrantes del equipo de investigación realizaron un análisis de contenido de la información recogida, incluyendo una revisión de su validez interna y externa, contrastada en una sesión participativa entre todas las personas integrantes del equipo de investigación.

\begin{tabular}{|c|c|}
\hline \multicolumn{2}{|r|}{ Tabla III: Instrumento de Valoración Metodológica } \\
\hline Categoría & $\begin{array}{c}\text { Guías/criterios de valoración } \\
\end{array}$ \\
\hline \multicolumn{2}{|r|}{ Valoración de aspectos éticos } \\
\hline Acogida & $\begin{array}{l}\text { ¿Cuál te parece que fue la acogida de niñas y niños de sobre el } \\
\text { Consentimiento Informado? ¿Les gustó la idea de leer y firmar/autorizar } \\
\text { por sí mismos/as? ¿Comentaron algo al respecto? }\end{array}$ \\
\hline Comprensión & $\begin{array}{l}\text { ¿Lo entendieron sin ayuda? ¿Tuviste que ayudarles a leerlo o a entenderlo? } \\
\text { El contenido: palabras, conceptos... }\end{array}$ \\
\hline Aspecto & ¿Les gustó el cómic en sí?, ¿el tipo de dibujo? \\
\hline Participación & $\begin{array}{l}\text { ¿Crees que facilitó su participación? ¿De qué manera? ¿Hubo niños/as } \\
\text { que decidieron no participar aún después de leer el cómic? ¿Explicaron } \\
\text { sus motivos? }\end{array}$ \\
\hline Innovación & ¿Hicieron alguna sugerencia sobre el cómic? \\
\hline Dudas & $\begin{array}{l}\text { ¿Los/as niños/as hicieron preguntas sobre el proyecto de investigación? En } \\
\text { caso positivo, ¿qué preguntaron? }\end{array}$ \\
\hline Conflictos éticos & $\begin{array}{l}\text { ¿Hay algún aspecto de la investigación que creas que es éticamente } \\
\text { cuestionable? } \\
\text { ¿Tuviste en algún momento, durante el desarrollo de la investigación, } \\
\text { algún conflicto ético o de otro tipo por tu participación en la misma? }\end{array}$ \\
\hline \multicolumn{2}{|r|}{ Valoración de aspectos metodológicos } \\
\hline \multicolumn{2}{|r|}{ Valoración de las sesiones grupales } \\
\hline Lugar & $\begin{array}{l}\text { ¿Ha sido apropiado? ¿Cuál te parece que sería el mejor lugar para realizar } \\
\text { estos grupos o entrevistas? }\end{array}$ \\
\hline Ambiente & $\begin{array}{l}\text { ¿Ha sido propicio, ha habido interrupciones? ¿Fue fácil o difícil que no } \\
\text { hubiera interrupciones? ¿Ha generado suficiente intimidad? }\end{array}$ \\
\hline Duración & A los/as niños/as, ¿se les ha hecho largo, corto...? \\
\hline Abandonos & $\begin{array}{l}\text { ¿Alguna niña o niño ha abandonado la sesión antes de darla por } \\
\text { terminada? ¿Cuál ha sido la razón? }\end{array}$ \\
\hline Acompañamientos & $\begin{array}{l}\text { ¿Han estado presentes otras personas? ¿Eso ha favorecido o ha dificultado } \\
\text { el desarrollo de la sesión? }\end{array}$ \\
\hline Actitud & ¿Han estado cohibidos/as, relajados/as, participativos/as...? \\
\hline Entretenimiento & $\begin{array}{l}\text { ¿Han disfrutado, se han aburrido? ¿En qué medida valoras necesario que } \\
\text { la sesión resulte entretenida? }\end{array}$ \\
\hline Liderazgos & $\begin{array}{l}\text { ¿Algún niño/a ha liderado el grupo, en sentido positivo o negativo } \\
\text { (manipulación)? }\end{array}$ \\
\hline $\begin{array}{l}\text { Relación } \\
\text { investigadora-niño/a }\end{array}$ & $\begin{array}{l}\text { ¿Has notado diferencias de poder respecto a las investigadoras? } \\
\text { ¿Cohibido? ¿Hubo un ambiente de confianza? }\end{array}$ \\
\hline Homogeneidad & ¿El grupo ha resultado homogéneo por sus características? \\
\hline
\end{tabular}




\begin{tabular}{|c|c|}
\hline \multicolumn{2}{|r|}{ Valoración de las técnicas creativas } \\
\hline Adecuación edad & $\begin{array}{l}\text { ¿Las técnicas han sido adecuadas para la edad de los/as niños/as? ¿Les } \\
\text { han parecido "infantiles" o lo contrario? Diferencia entre grupos de edad. }\end{array}$ \\
\hline $\begin{array}{l}\text { Adecuación estado de } \\
\text { salud }\end{array}$ & $\begin{array}{l}\text { ¿Las técnicas han sido adecuadas para el estado de salud de los/as niños/ } \\
\text { as? ¿Algún niño/a no ha podido realizar alguna de las actividades por su } \\
\text { estado de salud? Consideraciones prácticas a tener en cuenta para otros } \\
\text { estudios/otras ocasiones. }\end{array}$ \\
\hline Nivel de aceptación & $\begin{array}{l}\text { ¿Cuál ha sido el nivel de aceptación ante cada técnica? ¿Algún niño/a se ha } \\
\text { negado a realizar alguna? ¿Han propuesto cambios? }\end{array}$ \\
\hline Nivel de comprensión & $\begin{array}{l}\text { ¿Han comprendido bien la dinámica de la técnica? ¿Ha habido que } \\
\text { explicarla más veces o modificarla? }\end{array}$ \\
\hline Nivel de "disfrute" & $\begin{array}{l}\text { ¿Qué técnica les ha gustado más? ¿Cómo han valorado participar en estas } \\
\text { técnicas? }\end{array}$ \\
\hline Dinámica & ¿Qué técnica ha dado mejor resultado? En cuanto a dinámica, ¿cuál peor? \\
\hline $\begin{array}{l}\text { Generación de } \\
\text { información }\end{array}$ & $\begin{array}{l}\text { ¿Con qué técnica se ha obtenido más información, más útil, más } \\
\text { interesante? ¿Con cuál peor? ¿Coincide con la información obtenida a } \\
\text { través de entrevista u otras técnicas o difiere? }\end{array}$ \\
\hline Sesgos & $\begin{array}{l}\text { ¿Ha habido imitación en alguna de las técnicas? ¿Algún otro posible } \\
\text { sesgo? }\end{array}$ \\
\hline Estado emocional & $\begin{array}{l}\text { ¿Algún niño/a ha llorado con alguna técnica/tema? ¿Han expresado algún } \\
\text { otro tipo de sentimiento? ¿En qué momento? }\end{array}$ \\
\hline Diferencias de género & $\begin{array}{l}\text { ¿Ha habido diferencias en la recepción de las técnicas en función del } \\
\text { género? }\end{array}$ \\
\hline \multicolumn{2}{|r|}{ Valoración de la vivencia del proceso de investigación } \\
\hline Dificultad & $\begin{array}{l}\text { ¿Cuáles han sido los momentos o aspectos de especial dificultad en el } \\
\text { trabajo de campo? }\end{array}$ \\
\hline $\begin{array}{l}\text { Relación } \\
\text { de la persona } \\
\text { investigadora - niño/a }\end{array}$ & $\begin{array}{l}\text { ¿Cómo ha sido tu relación con estos niños y niñas? ¿Te ha parecido que } \\
\text { se cohibían contigo? ¿Te generó problemas trabajar con niños/as? ¿Y con } \\
\text { niños/as de Oncología Pediátrica? ¿Y con niños/as de Oncología Pediátrica } \\
\text { en fase avanzada? }\end{array}$ \\
\hline Innovación & $\begin{array}{l}\text { En un proyecto similar con niños/as y adolescentes hospitalizados/ } \\
\text { as, ¿cambiarías la metodología? ¿Utilizarías una similar? ¿Hay algo } \\
\text { relacionado con la utilización de las técnicas creativas y el manejo de } \\
\text { los aspectos éticos que resolverías de otra manera? ¿Tienes propuestas } \\
\text { concretas? }\end{array}$ \\
\hline
\end{tabular}

\section{RESULTADOS}

A continuación, se describe la evaluación del equipo de investigación de los aspectos éticos y metodológicos, así como la vivencia del proceso de investigación (Tabla IV-V). 


\begin{tabular}{|c|c|c|c|}
\hline 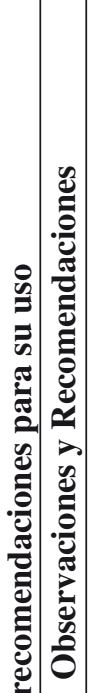 & 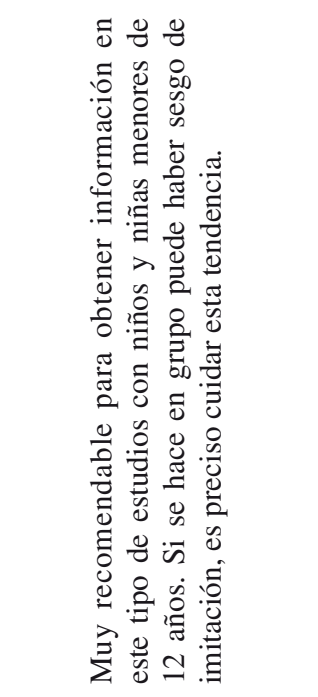 & 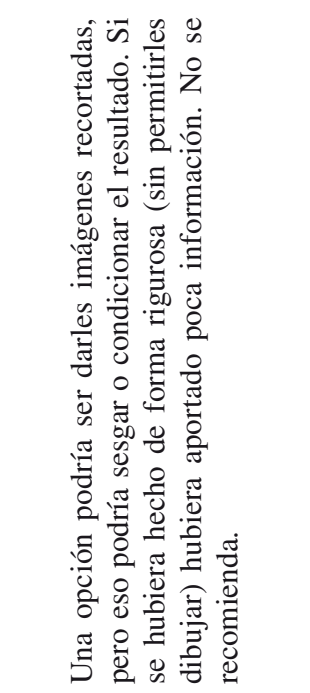 & 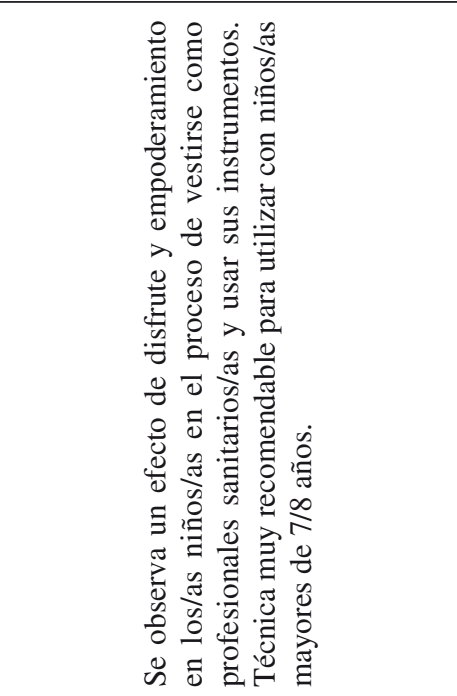 \\
\hline 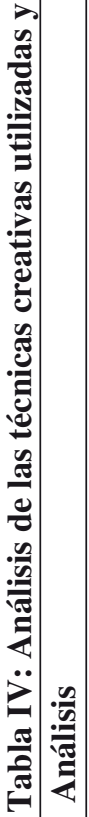 & 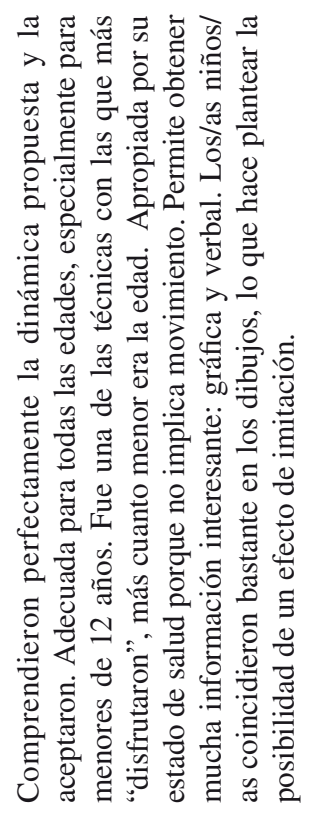 & 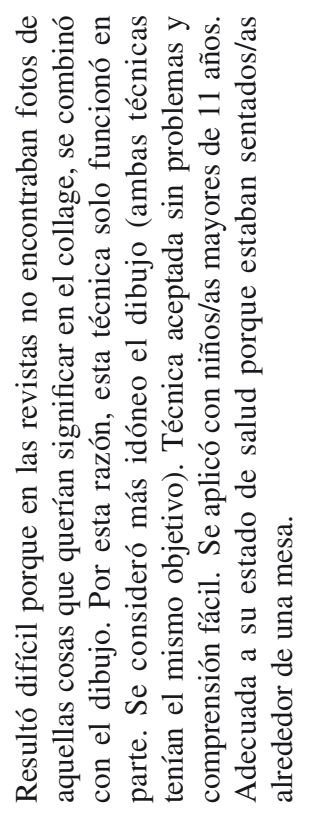 & 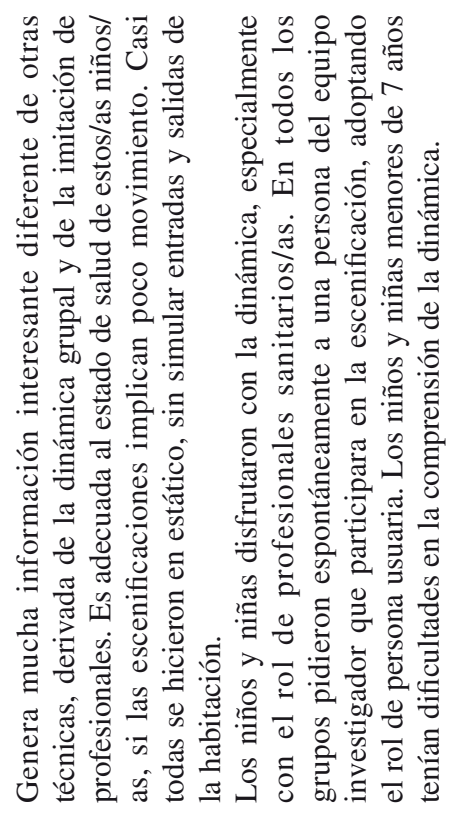 \\
\hline 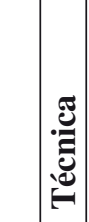 & $\frac{\stackrel{\circ}{\vec{B}}}{\stackrel{\overline{0}}{0}}$ & 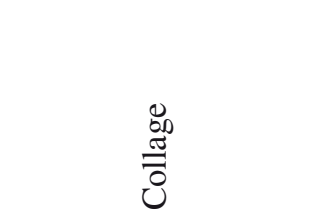 & 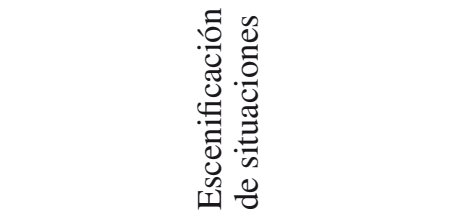 \\
\hline
\end{tabular}




\begin{tabular}{|c|c|c|c|c|c|}
\hline & 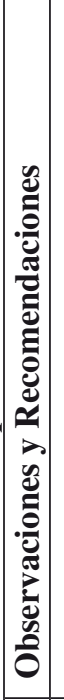 & 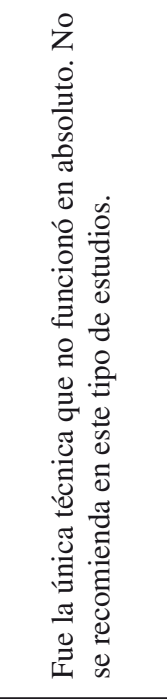 & 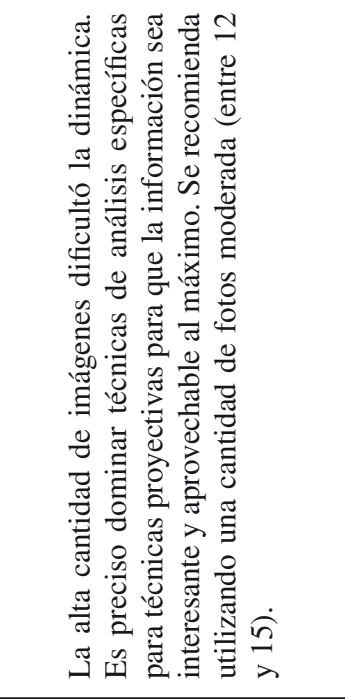 & 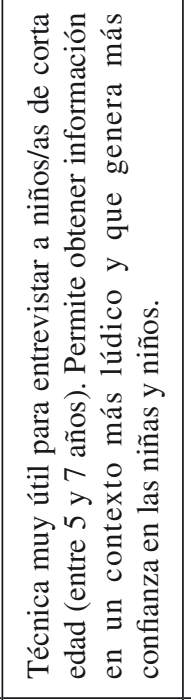 & 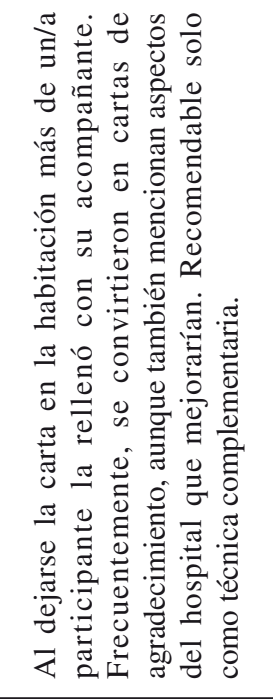 \\
\hline & 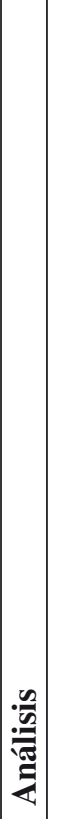 & 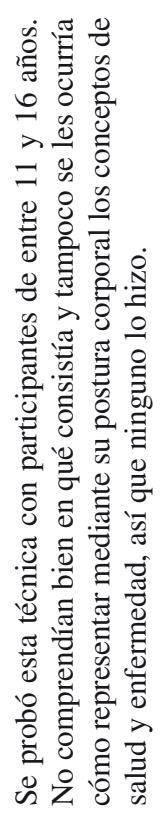 & 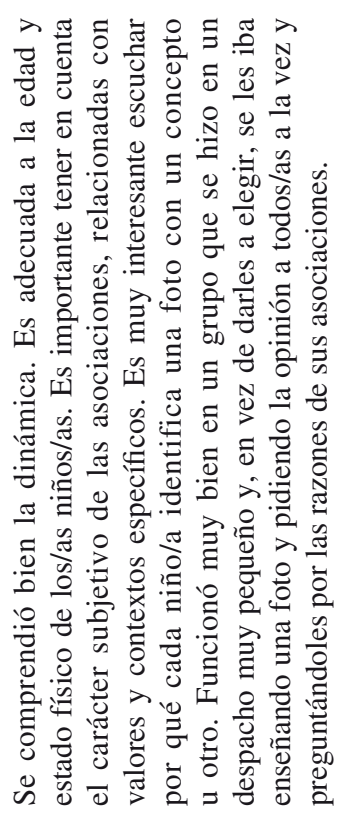 & 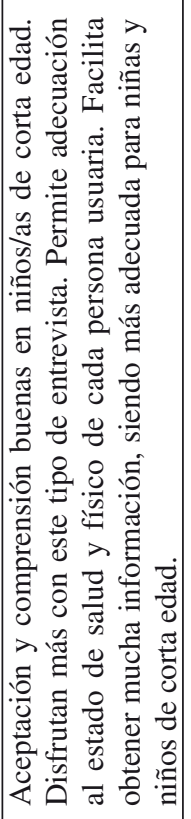 & 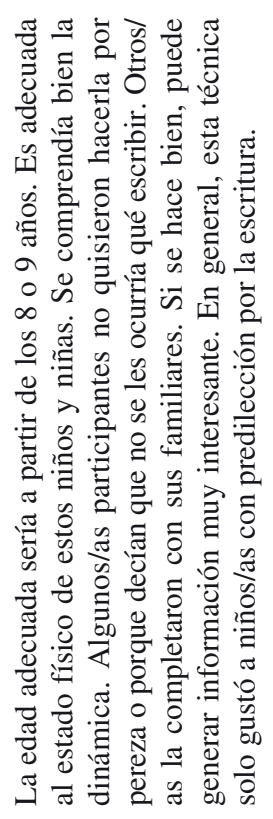 \\
\hline & 苞 & $\begin{array}{l}\text { ज़ } \\
\text { [I }\end{array}$ & 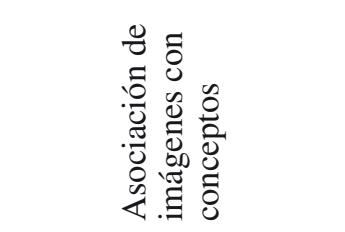 & 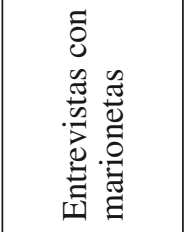 & 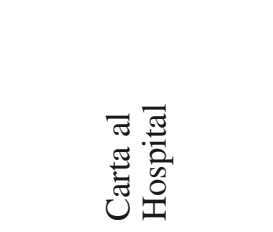 \\
\hline
\end{tabular}




\section{Tabla V: Evaluación del proceso de investigación realizada por el equipo investigador. Citas literales Aspectos éticos \\ Consentimiento Informado}

"Hubo una niña de 11 años en fase de enfermedad avanzada que fue muy expresiva cuando le dimos el Consentimiento Informado. Alzo los brazos, gritó de alegría, se volvió hacia su madre y le dijo algo como: 'mira, por fin voy a firmar yo en vez de tú'. Y dijo: ‘AAh! Eso sí me gusta porque los chicos nunca pueden firmar'."

\section{Conflictos éticos}

“Cuando se planteó el 'conflicto ético' de si era apropiado hacer esta investigación con niños y niñas..."

"Razones para el conflicto ético: Considerar que se les pedía más que se les daba."

\section{Aspectos metodológicos}

Técnicas grupales

"Las técnicas hechas en grupo parecían entretenerles más que individualmente, además la interacción entre ellos daba mucha información."

\section{Lugar}

"En la escuela del hospital, una sala muy pequeñita. La verdad que no era el lugar más adecuado porque es la única sala común de la planta y por lo tanto nos interrumpieron varias veces."

"Lo hicimos en el despacho del coordinador de la unidad. Muy pequeño y con el obstáculo del mobiliario de despacho. No fue nada adecuado, pero era la mejor opción porque en el aula de la planta no hubiéramos tenido ninguna confidencialidad. Está abierta."

\section{Técnicas creativas}

\section{Role-Playing}

"Se hizo con un grupo de 3 niños que se implicaron muy bien en la dinámica y les encantó hacer de médicos, se reían mucho y dieron mucha información."

"No pueden realizar mucho movimiento, por ejemplo para realizar el role playing ya que tienen la máquina del tratamiento continuamente conectada."

"Creo que con la que más disfrutaron fue la escenificación, ponerse en el papel de médicos, imitarles... se rieron mucho (nosotras también) y lo hacían muy bien."

Marionetas

"La técnica de marionetas, con otro niño más mayor sí funcionó muy bien, hablaba con el muñeco incluso de la investigadora como si no se encontrase allí ella... fue muy bonito ver esa interacción y dio mucha información."

Dibujo

"El dibujo fue una técnica muy adecuada porque se comunican muy bien a través de ella. Se nota que estaban acostumbrados a dibujar y les gustaba explicar lo que habían hecho y por qué."

Valoración general de las técnicas grupales

"Las técnicas que mejor han funcionado son las que a su vez más información generaron."

"He aprendido mucho de la forma que tienen los/as niños/as de comunicarse y de lo claro que expresan sus ideas y sentimientos mediante estas técnicas."

"La espontaneidad que pueden ofrecer estas técnicas permite obtener más claves sobre sus expectativas, opiniones, etc." 


\begin{tabular}{|c|}
\hline Vivencia del proceso de investigación \\
\hline Impacto emocional \\
\hline $\begin{array}{l}\text { "Al principio, es un impacto. Y al irte de allí te vas con bastante tristeza. Pero no tuve ningún } \\
\text { conflicto porque, en definitiva, son niños/as, con los que se puede jugar, hablar... y creo que lo } \\
\text { necesitan, de hecho." } \\
\text { "Más que conflicto ético recuerdo conflicto "emocional' o no sé cómo expresar la impotencia } \\
\text { de que sufran una enfermedad grave." } \\
\text { "A veces ir al hospital y ver gente pasándolo tan mal no fue fácil. Pero también era bonito } \\
\text { porque veías cómo lo afrontaban y cómo seguían con ánimo... e intentaba quedarme con esa } \\
\text { parte más positiva." } \\
\text { "Las noches anteriores y posteriores de insomnio y el agotamiento de las jornadas en el hospital } \\
\text { fue mucho mayor que en otras investigaciones con pacientes adultos/as." }\end{array}$ \\
\hline Oportunidades de aprendizaje \\
\hline $\begin{array}{l}\text { "Muy buena. Algunos/as me parecieron dignos de admiración y fue una experiencia muy } \\
\text { enriquecedora ver cómo niñas y niños tan pequeños afrontan la enfermedad y la hospitalización } \\
\text { y cómo se dan cuenta de todo y te lo explican todo con esa "normalidad' y esa serenidad. Ha } \\
\text { sido una lección." }\end{array}$ \\
\hline \begin{tabular}{|l} 
Habilidades necesarias \\
\end{tabular} \\
\hline $\begin{array}{l}\text { "En cualquier caso lo que sí creo que es muy importante es que seamos conscientes de nuestros } \\
\text { temores y limitaciones porque ni los/as niños/as ni los papas se merecen tener en frente a } \\
\text { alguien que no esté convencido de lo que hace o que sienta miedo y ganas de huir ante su } \\
\text { dolor." }\end{array}$ \\
\hline Aplicabilidad \\
\hline
\end{tabular}

\subsection{Valoración de los aspectos éticos}

El equipo coincidió en otorgar una especial importancia al cuidado de los aspectos éticos de la investigación. Estos aspectos incluyeron el proceso de Consentimiento Informado, la protección de la confidencialidad, el cuidado de un potencial impacto emocional del proceso de entrevista en las personas entrevistadas, así como la devolución de los resultados a las personas participantes interesadas. Como el aspecto más innovador se identifica la adaptación del formulario de Consentimiento Informado a las personas usuarias menores de edad, mediante la elaboración de un formulario en formato cómic (Gráficos 2 y 3).

Según la valoración del equipo de investigación, los/as niños/as acogieron de forma muy positiva el formulario de Consentimiento Informado en formato cómic. Se destaca su utilidad como vía de información sobre los objetivos y técnicas a realizar, así como un efecto de empoderamiento y reconocimiento del derecho a la participación de los/as niños/as, especialmente en la franja de edad hasta los 14 años. En este sentido, una chica de 11 de años resaltó que en dos años de tratamiento era la primera vez que tenía oportunidad de firmar un Consentimiento Informado (“¡Ah! Eso sí me gusta porque los chicos nunca 
pueden firmar"). En cambio, los/as jóvenes de 15 y 16 años parecían recibir la hoja con una mayor indiferencia.

Respecto a la comprensión del formulario, en caso de los/as niños/as más pequeños/as con dificultades lectoescritoras (menores de 7 años) era necesario un apoyo para leerlo y comprenderlo. Algunos/as de los/as niños/as de $8-9$ años preferían leerlo junto con alguna persona del equipo investigador, por la posibilidad de plantear preguntas. Varios/as niños/as decidieron no participar después de recibir información sobre el estudio y la hoja de Consentimiento Informado en formato de cómic, alegando que no tenían ganas o ánimo, o porque su estado físico no se lo permitía.

Partiendo de la experiencia del presente estudio, el equipo de investigación desarrolló recomendaciones para el abordaje de los aspectos éticos en proyectos de investigación cualitativa con personas menores de edad en situación de enfermedad grave. Entre otros aspectos, se resalta la importancia de un proceso de información exhaustiva sobre el proyecto dirigido las personas acompañantes en la fase previa al trabajo de campo en el hospital, una información detallada dirigida a los/as niños/as y la vigilancia de que ninguna persona participe solo por petición o presión del personal sanitario. Como otro aspecto ético relevante se señala plantear todos los temas de forma más cuidadosa posible, especialmente a participantes en situación terminal y en general cuando se habla de los miedos, del futuro y de otros aspectos delicados.

\subsection{Valoración de los aspectos metodológicos}

\subsubsection{Valoración de las sesiones grupales}

El enfoque metodológico del estudio prevé la participación de cada niño y niña tanto en una sesión individual como en una sesión grupal. En su evaluación, las integrantes del equipo investigador coincidieron que no hubo problemas para realizar sesiones individuales con la mayoría de los y las participantes. Sin embargo, la realización de los grupos se identifica como el aspecto de mayor dificultad en el planteamiento metodológico, debido a la dificultad de encontrar a niños y niñas del mismo grupo de edad y fase de enfermedad, con ingreso simultáneo, que estuvieran en buenas condiciones físicas y emocionales, no tuvieran que realizar pruebas en el día acordado y que dieran el consentimiento para participar. Esta dificultad contribuyó a que se pudieran realizar un número de grupos menor del que estaba proyectado y también que se adaptase el número mínimo de participantes, realizando grupos con dos o tres participantes.

Las personas integrantes del equipo de investigación coinciden en valorar el ambiente de desarrollo de las sesiones en grupo como agradable y distendido, con bastante intimidad y confianza. En caso de que la planta dispusiera de una sala de escuela, la sesión se realizó en este espacio. El equipo valora que el lugar idóneo para realizar estas sesiones grupales sería amplio, luminoso, conocido por los niños y niñas, con mobiliario adecuado, que facilitara un ambiente 
lúdico y permitiera evitar interrupciones. Respecto a la duración media de las sesiones grupales (aproximadamente una hora), se expresan diferentes opiniones. Mientras algunas personas en el equipo de investigación consideran que fue adecuada, otras valoran que la sesión debería haber sido más corta, proponiendo la realización de tres técnicas creativas en vez de cuatro por sesión.

En ninguno de los grupos realizados hubo abandonos de la sesión. En un grupo, una niña tuvo que interrumpir la participación en la dinámica por sentirse mareada. Se incorporó de nuevo al recuperarse. En dos de los grupos hubo varias interrupciones par parte de familiares o profesionales. Según la valoración del equipo, estas interrupciones se debían ante todo a la falta de adecuación del lugar. Tres de los niños y niñas de menor edad (cinco y seis años) que acudieron a las sesiones grupales lo hicieron con acompañamiento de su madre o padre. El equipo de investigación coincide en valorar este acompañamiento como apoyo y no como intromisión en el desarrollo de la sesión, por darles una sensación de seguridad a los/as niños/as.

Respecto a la capacidad de entretenimiento de la sesión grupal se señala que todos y todas participantes disfrutaron con las técnicas. Se identifica un mejor funcionamiento de las sesiones grupales en la franja de edad de 5-6 y 7-10 años, a diferencia de la franja de 11-16 años. Además, el equipo destaca la importancia de que las edades sean lo más similares posibles para el funcionamiento del grupo. En cuanto a la fase de enfermedad, no se aprecian diferencias con relación a la interacción en el grupo.

\subsubsection{Valoración de las técnicas creativas}

Las técnicas creativas se aplicaron tanto en sesiones individuales como grupales. La valoración de cada una de las técnicas utilizadas se puede consultar en la tabla IV. A continuación, se resume la valoración global de su uso.

Las personas integrantes del equipo investigador coinciden en señalar la importancia de que las técnicas creativas se adapten al estado físico de las personas usuarias. Según su valoración, han de ser técnicas que impliquen poco movimiento para cuidar que las personas usuarias no tengan que hacer un esfuerzo excesivo y por el uso de soportes portasueros que dificulta su movilidad. Destacan que, en el caso del presente estudio, la única técnica que implicaba acción fue la escenificación, pero se realizó de forma estática, con poco movimiento y más centrada en los diálogos que en la expresión corporal.

Respecto a la adaptación de las técnicas a la edad, el equipo investigador destacó que los/as niños/as de 5 y 6 años participaron en las técnicas de entrevista con marionetas, dibujo, cine-foro y asociación de imágenes con conceptos, no así en la escenificación cuya dinámica no comprendieron. Por otra parte, los/as niños/as más mayores (mayores de 12 años) se implicaron menos en las dinámicas con técnicas creativas, alegando desinterés u otras razones. El equipo maneja la hipótesis de que las encontraban 'infantiles'. 
Respecto a la fase de enfermedad, se observaron limitaciones en la participación en caso de personas usuarias en estado de enfermedad avanzada, a la vez de constatarse un efecto de distensión y ruptura de la monotonía cuando podían participar en las sesiones grupales y técnicas creativas.

Con relación al nivel de disfrute o entretenimiento, las técnicas creativas realizadas en grupo parecían entretener más que las realizadas en sesiones individuales, por resultar más lúdicas. El equipo investigador valora la interacción grupal en sí como una fuente importante de información. Además, destaca que el nivel de distensión influía positivamente en la participación y la obtención de información relevante.

A modo general, el equipo de investigación coincide en que el uso de las técnicas creativas no propició alteraciones en el estado emocional de los niños y niñas, sino ayudó a expresar o experimentar emociones positivas (alegría, relajación, risa). Sin embargo, en las entrevistas individuales, en algún caso se dio lugar a alguna expresión emocional, como la expresión de rabia (por estar en el hospital, por perderse cosas que pasaban fuera) o de llanto (por recordar la imposibilidad de salir del hospital durante la realización de un dibujo). El equipo coincide en identificar las escenificaciones como la técnica con la que más parecían disfrutar los niños y niñas entre 7 y 11 años, por posibilitar ponerse en el papel de sus profesionales, seguido por la técnica de dibujos y marionetas. De las técnicas previstas, la única que no funcionó en absoluto y hubo que desechar fue la técnica de estatuas.

El equipo señala que, en general, no se produjeron efectos de contagio entre las personas participantes. A la vez mencionan que, en caso de la técnica de dibujos, les resultó difícil discernir si la presencia de motivos parecidos en las imágenes se debe a la expresión de vivencias similares o a un proceso de imitación.

En cuanto a la generación de información, el equipo de investigación indica que la mayoría de las técnicas creativas produjeron información similar y redundante con la que aporta la entrevista semiestructurada, aparte de la escenificación de situaciones cotidianas del hospital que proporcionó información que no aparece tan claramente en las entrevistas.

En general, la valoración del equipo de investigación sobre la utilización de las técnicas creativas en este tipo de estudios es positiva, a la vez de resaltar la necesidad de planificar adecuadamente su aplicación. Recomienda su uso en niños y niñas menores de 12 años por facilitar la expresión, aportar información complementaria, aumentar el componente lúdico, así como por coincidir con actividades habituales de los niños y niñas. El equipo observó una expresión clara de ideas, opiniones y sentimientos de las personas participantes mediante las técnicas creativas.

El equipo de investigación recomienda el uso de estas técnicas siempre que se cumplan algunas condiciones, entre ellas su planificación detallada, la presencia de objetivos claros, el carácter sencillo y breve de las dinámicas y la claridad respecto al procedimiento de análisis. El refuerzo de los resultados creativos con aclaraciones verbales, así como la disposición de conocimientos 
metodológicos específicos para el análisis de los datos creativos se considera importante para evitar una interpretación errónea. En este sentido, las técnicas creativas se proponen como apoyo y pretexto para el comentario verbal. En cambio, el equipo de investigación no recomienda especialmente el uso de las técnicas creativas con jóvenes mayores de 12 años. Con este grupo de edad, se observa un mejor funcionamiento de las entrevistas semiestructuradas.

\subsection{Vivencia del proceso de investigación}

La valoración global del proceso de trabajo de campo por parte del equipo investigador fue positiva. Se describe el proceso como experiencia interesante y enriquecedora. Las personas integrantes del equipo investigador reflejan la percepción de que los/as participantes disfrutaron de la experiencia, por poder hablar de su situación, jugar con otros/as niños/as y salir de su habitación para realizar una actividad diferente que rompe la rutina hospitalaria. Asimismo, se valora positivamente la generosidad de los/as familiares al permitir a sus hijos/ as hablar con el equipo investigador en privado, dando su confianza a que se abordaran los temas delicados de forma cuidadosa.

El equipo investigador coincide en describir la relación investigador/aparticipante de forma muy positiva. Se describe un proceso de establecimiento y consolidación de la relación entre la persona investigadora y los/as participantes, caracterizada por un paso desde una cierta timidez hacia la creación de una relación de confianza.

A la vez, el equipo retrata un especial impacto emocional durante el trabajo de campo con los y las niños en Oncología Pediátrica. Relatan haber vivido un mayor agotamiento que en otras investigaciones, incluyendo episodios de insomnio anterior y posterior al trabajo de campo. Como aspectos de especial dificultad emocional en el proceso investigador se menciona presenciar cuando una persona participante llora durante la entrevista, encontrar las palabras y expresiones precisas para cuidar el aspecto emocional de las interacciones, abordar sensaciones de impotencia ante la situación de enfermedad grave, así como afrontar los miedos y las preocupaciones ante la enfermedad y la muerte, especialmente en caso de personas en situación terminal. A la vez, valoran la experiencia como una oportunidad de aprendizaje, al presenciar la capacidad de afrontamiento de los niños y niñas.

Aparte de los aspectos nombrados, algunas personas integrantes del equipo de investigación reflexionan acerca de si la investigación es de utilidad, teniendo en cuenta la actual situación económica. Otras personas del equipo reflejaron la vivencia de una sensación de conflicto en el contacto con niños/as en situación terminal, por conocer el pronóstico, a diferencia de los/as niños/as, así como por tener la sensación de pedir más a los/as niños/as de lo que se les daba.

A modo de conclusión, las personas del equipo de investigación resalta la importancia de ser conscientes de los propios temores y limitaciones, por considerar que las personas participantes se merecen un equipo investigador 
seguro de su trabajo y con capacidad para llevarlo a cabo con solvencia y empatía, así como de tener habilidades o experiencia en el manejo emocional y el abordaje del llanto. Además, señalan la relevancia de una traducción de los resultados del estudio en la mejora de la atención sanitaria de este grupo de usuarios/as.

\section{DISCUSIÓN}

Como limitaciones del presente estudio se puede identificar la dificultad en la convocatoria de los grupos, debido a las características de la situación de hospitalización y el estado de salud de las personas participantes; así como la falta de privacidad en el espacio disponible para la realización de los grupos con las personas usuarias menores de edad, de potencial influencia en las opiniones expresadas. Además, en caso de la técnica de dibujos, se observó un efecto de imitación entre los y las niños que puede causar un sesgo en los resultados. Desde la discusión de las limitaciones y aspectos de dificultad experimentados durante el estudio, el equipo de investigación elaboró recomendaciones para futuras investigaciones.

Respecto a los aspectos éticos, el equipo investigador resalta la importancia de tener en cuenta su cuidado durante diferentes fases del estudio, especialmente respecto a la provisión de una información exhaustiva sobre los objetivos del estudio, la garantía de confidencialidad, el proceso de Consentimiento Informado, el cuidado de aspectos emocionales y la devolución de resultados. La valoración de la importancia de estos aspectos coincide con análisis previos sobre aspectos relevantes de una ética de la investigación con personas menores de edad (Corporació Taulí 2003; De Abajo 1997; Galende 2012; Mack, Giarelli y Bernhardt 2009; Mason y Hood 2011; Pickler 2010; Sammons y Starkey 2011; Shaw, Brady y Davey 2011; Wellesley y Jenkins 2012; Wilkinson 2000; Ybarra et al. 2009).

En el presente estudio, se observaron, en algunos momentos, reacciones emocionales que reafirman la importancia de un abordaje adecuado de un potencial impacto emocional del proceso de entrevista con menores de edad, mencionado en publicaciones anteriores (Wilkinson 2000; Ybarra et al. 2009). A la vez, en el presente estudio, de forma parecida a trabajos previos (Wilkinson 2000), se observan efectos de disfrute y empoderamiento, especialmente en la técnica de escenificación, en la que los/as niños/as a menudo eligieron representar el rol de profesionales de la salud.

Como aspecto innovador del presente estudio se puede nombrar el uso del Consentimiento Informado en formato de cómic. Su disponibilidad fue evaluada de forma positiva por las personas participantes, por recibir información sobre el estudio y facilitar una posibilidad de decisión, a diferencia de la percepción de falta de oportunidades de participación durante la estancia en el hospital. En algunos niños y niñas el proceso de firma del Consentimiento Informado aumentó su disposición a participar. Otros/as hicieron uso de su derecho a no 
participar, independientemente del consentimiento por parte de los padres y madres. La observación de un interés de recibir información y de una toma de decisión activa sobre la participación o no participación en el estudio, se puede poner en relación con el reconocimiento del derecho de las personas menores de edad a la información y participación en el ámbito sanitario, reconocido tanto desde enfoques de ética de la investigación (Duncan et al. 2009; Shaw, Brady, Davey 2011; Wellesley y Jenkins 2012; Wilkinson 2000), como desde perspectivas de Derechos Humanos (ONU 1989 [1990], 2005, 2009, 2013).

Las personas menores de edad entrevistadas en el presente estudio mostraron opiniones claras sobre la calidad asistencial recibida y el trato deseado por los y las profesionales de la salud, una característica observada también en trabajos anteriores (Carter y Ford 2013; Einarsdottir 2005; Kondo y Sjöberg 2012; March et al. 2003; Trell y Van Hoven 2010; Ullán et al. 2012; Wilkinson 2000).

Respecto a los aspectos metodológicos, la utilización de las técnicas creativas se consideró de utilidad para el contexto de un análisis de las opiniones y expectativas de personas usuarias menores de edad sobre la calidad asistencial percibida. Esta observación se encuentra en coherencia con estudios anteriores que exploran la percepción de la calidad asistencial de personas usuarias menores de edad a través de metodologías creativas (González-Gil 2007; March et al. 2003).

A la vez, se señala la necesidad de un aplicación diferenciada y focalizada de las técnicas creativas, nombrada también en otros trabajos (Wilkinson 2000). En este sentido, se indica la necesidad de tener en cuenta la edad de las personas menores de edad, observándose una mayor adecuación de las técnicas creativas en caso de los y las niños menores de 12 años, frente a la preferencia de niños/as más mayores a la expresión verbal o por escrito. Estos resultados coinciden con estudios previos con personas menores de edad que observan el riesgo de una percepción de las técnicas creativas como 'infantiles' (Wilkinson 2000), proponiendo una aplicación diferenciada de las metodologías por grupo de edad (Kondo y Sjöberg 2012; Wilkinson 2000). En estudios previos (González-Gil 2007), se describe la utilidad de un uso de marionetas en el grupo de niños y niñas más jóvenes, observada también en el presente estudio. Como otro aspecto destacado, en el presente estudio se señala la importancia de adecuar las técnicas a la situación de movilidad reducida de algunas de las personas participantes.

En general, en el presente estudio se observan resultados parecidos obtenidos a través de las técnicas creativas que a través de técnicas verbales, con la excepción del role playing, que aportó aspectos diferenciales. Trabajos previos (Wilkinson 2000) coinciden en la valoración de la utilidad de la aplicación del role playing, a la vez de señalar la necesidad de su aplicación cuidadosa, para asegurar la participación de todo el grupo.

Como otro resultado destacable del presente estudio, se puede señalar la importancia de acompañar la técnica creativa por la expresión verbal, con el objetivo de conocer la interpretación de los y las niños sobre su propia creación (Wilkinson 2000). En este sentido, la técnica creativa adquiere un rol 
de apoyo a la expresión verbal de opiniones y expectativas (Johnson y Well 2001). Coincidiendo con trabajos anteriores (Carter y Ford 2013), el equipo señala la importancia de reflexionar sobre la influencia de los métodos creativos en el proceso de análisis de datos, así como de disponer de una preparación metodológica adecuada.

Respecto a la descripción autorreflexiva sobre el proceso de investigación, el equipo de investigación expresa diferentes dudas, relacionadas tanto con el impacto emocional del proceso de investigación en los/as niños/as, los límites de reciprocidad y la pregunta por la utilidad y aplicabilidad del estudio. Además, los relatos reflejan la vivencia de sensaciones de insomnio y agotamiento en el equipo durante el trabajo de campo ante la presencia de situaciones de enfermedad grave en menores de edad.

La realización de un proceso de autoevaluación de las técnicas metodológicas, los aspectos éticos y la vivencia del proceso de investigación se identificaron como elementos relevantes para la realización de futuros proyectos de investigación. Asimismo, se resaltó la importancia de un entendimiento de la ética de investigación no limitada a la firma del Consentimiento Informado, sino inherente a todo el proceso de investigación, en coherencia con un modelo de práctica reflexiva en la investigación social contemporánea (Canella y Lincoln 2007).

Las recomendaciones realizadas por el equipo de investigación sobre aspectos éticos y metodológicos en una investigación cualitativa con menores de edad en situación de enfermedad grave, entre ellas realización de un proceso exhaustivo de información antes del comienzo del trabajo de campo, el cuidado de evitar una influencia de los/as profesionales en la disposición a participar, el abordaje adecuado del impacto emocional, la focalización en la aplicabilidad de los resultados en la práctica clínica, la necesidad de una preparación profesional adecuada del equipo investigador, así como la aplicación diferenciada y focalizada de las técnicas creativas, se encuentran en coherencia con principios éticos y recomendaciones metodológicas establecidas en estudios anteriores (Carter 2009; Carter y Ford 2013; Chen y Shepard 2009; Coad, Plumridge y Metcalfe 2009; Corporació Taulí 2003; De Abajo 1997; Einarsdottir 2005; Galende, 2012; González-Gil 2007; Kondo y Sjöberg 2012; Mack, Giarelli y Bernhardt 2009; Mand 2012; Mason y Hood 2011; Part y Grayson 2008; Pickler 2010; Sammons y Starkey 2011; Shaw, Brady y Davey 2011; Trell y Van Hoven 2010; Wellesley y Jenkins 2012; Wilkinson 2000; Ybarra et al. 2009).

\section{CONCLUSIONES}

Desde el reconocimiento de la especial vulnerabilidad de personas menores de edad, la consideración de los aspectos éticos específicos adquiere una especial relevancia en estudios con este grupo de población. La propuesta de un Consentimiento Informado dirigido a los niños y niñas en formato de cómic, de forma paralela al consentimiento realizado por sus tutores legales, responde 
al reconocimiento del derecho a la información, participación y protección de personas menores de edad, establecido desde perspectivas éticas (Carter 2009; Chen y Sheperd 2009; Duncan et al. 2009; Part y Grayson 2008; Sammons y Starkey 2011; Shaw, Bray y Davey 2011; Wellesley y Jenkins 2012), el marco internacional de Derechos Humanos relacionado con la infancia (ONU 2005, 2009, 2013), así como enfoques de participación en la investigación con menores de edad (Wilkinson 2000).

El uso de metodologías creativas para conocer las opiniones y expectativas de personas usuarias menores de edad se identifica como una herramienta de utilidad, a la vez de señalarse la importancia de su aplicación diferenciada según la edad de las personas participantes, así como la disponibilidad de conocimientos metodológicos adecuados en el proceso de análisis de los materiales creativos. En este sentido, se recomienda el uso de técnicas creativas en niños y niñas de 11 años o menos. Con niños/as mayores de 12 años se observaba un mejor funcionamiento de técnicas cualitativas "clásicas" como la entrevista. Por franjas de edad, para niños/as de entre 5 y 7 años se recomienda el uso de la entrevista con marionetas, dibujo, cine-fórum y asociación de imágenes y conceptos; para niños/as de entre 8 y 11 años se propone también la técnica de escenificación con la que disfrutaron especialmente en el marco del presente estudio.

El uso de estas técnicas creativas no es un fin en sí mismo, siempre ha de estar justificado y en coherencia con los objetivos de la investigación. Además, es importante de que las técnicas creativas estén planificadas en detalle en función de objetivos y contenidos, adaptadas al estado físico de las personas participantes y basadas en un procedimiento sencillo. Asimismo, se recomienda que tengan un carácter lúdico, sirvan para la obtención de información y cuenten con un plan de análisis establecido de antemano. Por otra parte, las sesiones individuales resultaron más sencillas de realizar que las grupales por las características asociadas al estado de salud de los/as niños y niñas participantes. Las sesiones grupales se redujeron a grupos triangulares o a parejas y tuvieron la ventaja de resultar mucho más lúdicas y hacerles disfrutar más, a la vez que proporcionaron información muy rica. Se recomienda una duración máxima de las sesiones de 45 minutos (sean individuales o grupales) y la aplicación de un máximo de tres técnicas creativas por sesión.

La inclusión de un proceso de autorreflexión en la vivencia del equipo investigador, incluyendo una revisión de aspectos éticos y metodológicos, así como de la vivencia del proceso del trabajo de campo, se encuentra en consonancia con enfoques de ética reflexiva y dialógica (Cannella y Lincoln 2007) que parten de un entendimiento de la ética como un proceso continuado que atraviesa todas las fases del proyecto de investigación.

El conocimiento de la perspectiva de personas usuarias menores de edad sobre la calidad asistencial percibida se considera una herramienta relevante para la mejora de la atención hospitalaria a este grupo de población. 


\section{AGRADECIMIENTOS}

Nuestros agradecimientos a los niños y niñas que participaron en el estudio, sus acompañantes, así como a los y las profesionales que facilitaron la realización del trabajo de campo en las Unidades de Oncología Pediátrica.

\section{BIBLIOGRAFÍA}

AMEZCUA, M. y A. GÁLVEZ TORO (2002): "Los modos de análisis en investigación cualitativa en salud: Perspectiva crítica y reflexiones en voz alta", Rev Esp Salud Pública, 76(5), pp. 423-436.

ÅNGSTRÖM-BRÄNNSTRÖM, C., A. NORBERG y L. JANSSON (2008): "Narratives of Children with Chronic Illness about Being Comforted", Journal of Pediatric Nursing, 23(4), pp. 310-316.

BARRIO-CANTALEJO, I.M. y P. SIMÓN-LORDA (2006): "Problemas éticos de la investigación cualitativa”, Medicina Clínica, 126(11), pp. 418-423.

BEECHER, H.K (1966): "Ethics and Clinical Research", New England Journal of Medicine, 274, pp. 1354-1360.

CANNELLA G.S. e Y.S. LINCOLN (2007): "Predatory vs. Dialogic Ethics Constructing an Illusion or Ethical Practice as the Core of Research Methods", Qualitative Inquiry, 13(3), pp. 315-335.

CARTER, B. y K. FORD (2013): "Researching children's health experiences: The place for participatory, child-centered, arts-based approaches", Research in Nursing \& Health, 36(1), pp. 95-107.

CARTER, B. (2009): "Ticket box for child? The ethical positioning of children as vulnerable, researchers as barbarians and reviewers as overly cautious", International Journal of Nursing Studies, 46, pp. 858-864.

CHEN, D.T. y L.L. SHEPERD (2009): "When, Why and How to Conduct Research in Child and Adolescent Psychiatry: Practical and Ethical Considerations", Psychiatr Clin, 32, pp. 361-380.

COAD, J, G. PLUMRIDGE y A. METCALFE (2009): "Involving children and young people in the development of art-based research tools", Nurse Researcher, 16(4), pp. $56-64$.

CONDE, F. y C.P. ANDRÉS (1995): "La investigación cualitativa en Salud Pública", Rev Esp Salud Pública, 69, pp. 145-149.

CORPORACIÓ PARC TAULÍ, Comité de Ética Asistencial (2003): Orientaciones para evaluar la capacidad, Sabadell, Corporació Parc Taulí.

CURTIS, K., K. LIABO, H. ROBERTS y M. BARKER (2004): "Consulted but not heard: a qualitative study of young people's views of their local health service", Health Expectations, 7(2), pp. 149-156.

DE ABAJO, F.J. (1997): "Investigación clínica en niños: fundamentación y requisitos éticos", Rev Esp Pediatr, 53, pp. 134-150.

DUNCAN, R.E., S.E. DREWA, J. HODGSON y S.M. SAWYER (2009): "Is my mum going to hear this? Methodological and ethical challenges in qualitative health research with young people”, Social Science \& Medicine, 69, pp. 1691-1699.

EINARSDOTTIR, J. (2005): "Playschool in pictures: children's photographs as a research method", Early Child Development and Care, 175(6), pp. 523-541. 
FINLEY, S. (2011): “Arts-Based Inquiry”, en The Sage Handbook for Qualitative Research, London, Sage Publications, pp. 681-594.

GALENDE DOMÍNGUEZ, I. (2012): "Ética e investigación clínica en Pediatría", Pediatr Integral, XVI(4), pp. 342.e1-342.e.8.

GIBSON, F., S. ALDISS, M. MORSTMAN, S. KUMPUNEN y A. RICHARDSON (2010): "Children and young people's experiences of cancer care: A qualitative research study using participatory methods", International Journal of Nursing Studies, 47, pp. 1397-1407.

GOLDBY, S. (1971): "Experiments at the Willowbrook State School”, Lancet, pp. 749.

GONZÁLEZ-CARRIÓN, P. (2005): "Experiencias y necesidades percibidas por los niños y adolescentes con cáncer y por sus familias", Nure Investigación, 16, pp. $1-15$.

GONZÁLEZ-GIL, T. (2007): "Las marionetas como recurso para la realización de entrevistas en profundidad con niños preescolares", Enferm Clinic, 17(4), pp. 211216.

JOHNSON, J.C. y S.C. WELL (2011): "Elicitation Techniques for Interviewing", en Handbook of Interview Research, Thousand Oaks, London, New Delhi, Sage Publications, pp. 491-514.

KNOWLES, J.G. y A.L. COLE, eds. (2008): Handbook of the Arts in Qualitative Research. Perspectives, Methodologies, Examples, and Issues, Thousand Oaks, SAGE Publications.

KONDO, K. y U. SJÖBERG (2012): “Children's Perspectives through the Camera Lens. Reflections on Meaning-making Processes and Participatory Research", Nordicom Review, 33(1), pp. 3-18.

MACK, R., E. GIARELLI y B.A. BERNHARDT (2009), “The Adolescent Research Participant: Strategies for Productive and Ethical Interviewing”, J Pediatr Nurs, 24(6), pp. 448-457.

MAH, J.K., S. TOUGH, T. FUNG, K. DOUGLAS-ENGLAND y M. VERHOEF (2006): "Adolescent quality of life and satisfaction with care", Journal of Adolescent Health, pp. 28:607.e1-607.e7.

MAND, K (2012): “Giving children a 'voice': arts-based participatory research activities and representation", International Journal of Social Research Methodology, 15(2), pp. 149-160.

MARCH, JC, MA PRIETO, F. MARTÍNEZ y C. GUERRERO (2003): KID’S Hospital: La calidad percibida por los niños y niñas de los hospitales de Andalucía, Hitos de Ciencias Económico Administrativas, 23, pp. 25-30.

MASON, J. y S. HOOD (2011): "Exploring issues of children as actors in social research". Children and Youth Services Review, 33, pp. 490-495.

MCNIFF, S. (1998): Art-Based Research, London, Jessica Kingsley Publisher.

ONU, Organización de las Naciones Unidas, Asamblea General (1989 [entrada en vigor 1990]): Convención sobre los Derechos del Niño, disponible en http://www2.ohchr. org/spanish/law/crc.htm [consulta: 20/04/2016].

ONU, Organización de las Naciones Unidas, Comité sobre los Derechos del Niño (2005): Observación General No 7 (2005): Realización de los derechos del niño en la primera infancia, disponible en http://www2.ohchr.org/english/bodies/crc/docs/ AdvanceVersions/GeneralComment7Rev1 sp.pdf [consulta: 20/04/2016].

ONU, Organización de las Naciones Unidas, Comité sobre los Derechos del Niño (2009): Observación General No 12 (2009): El derecho del niño a ser escuchado, disponible en 
http://www2.ohchr.org/english/bodies/crc/docs/AdvanceVersions/CRC-C-GC-12 sp.doc [consulta: 20/04/2016].

ONU, Organización de las Naciones Unidas, Comité sobre los Derechos del Niño (2013): Observación General № 15 (2013) sobre el derecho del niño al disfrute del más alto nivel posible de salud (artículo 24), disponible en:

http://www2.ohchr.org/english/bodies/crc/docs/GC.15-Sp.pdf [consulta: 20/04/2016].

PART, S.S. y M.H. GRAYSON (2008): "Clinical research: Protection of the 'vulnerable'?", J Allergy Clin Immunol, 121, pp. 1103-1107.

PICKLER, R.H. y A.T. MARTIN (2010): "Protection of Children in Research", J Pediatr Health Care, 24, pp. 66-68.

SAMMONS, H.M. y E.S. STARKEY (2011): "Ethical issues of clinical trials in children", Paediatrics and Child Health, 22:2.

SHAW, C., L.-M. BRADY y C. DAVEY (2011): Guidelines for Research with Children and Young People, NCB Research Centre, London, National Children's Bureau.

TEUNISSEN, T., M. VISSE, P. DE BOER y T.A. ABMA (2011): "Patient issues in health research and quality of care: an inventory and data synthesis", Health Expectations, doi: 10.1111/j.1369-7625.2011.00718.x

TRELL, E.-M. y B. VAN HOVEN (2010): "Making sense of place: exploring creative and (inter)active research methods with young people", Fennia, 188(1), pp. 91-104.

ULIN, P.R., E.T. ROBINSON y E.E. Tolley (2006, eds.): Investigación aplicada en salud pública. Métodos cualitativos, Washington, OPS, Organización Panamericana de la Salud.

ULLÁN, A.M., M.H. BELVER, I. SERRANO, J. DELGADO y M. BADÍA (2012): "Perspectives of Youths and Adults Improve the Care of Hospitalized Adolescents in Spain", J Pediatr Health Care, 26, pp. 182-192.

WELLESLEY, H. y I.A. JENKINS (2012): Consent in children. Anaesthesia and Intensive Care Medicine, 13(5), pp. 240-242.

WILKINSON, J (2000): Children and Participation: Research, monitoring and evaluation with children and young people, London, Save the Children.

WOODGATE, R.L. y L. F. DEGNER (2003): "Expectations and beliefs about children's cancer symptoms: perspectives of children with cancer and their families", Foro de Oncol Nur, 30, pp. 479-491.

YBARRA, M.L., J. LANGHINRICHSEN-ROHLING, J. FRIEND y M. DIENERWEST (2009): "Impact of Asking Sensitive Questions about Violence to Children and Adolescents", J Adolesc Health, 45(5), 499-450. 